\title{
Expert Survey on the Prevention and Treatment Situation of Traditional Chinese Medicine for Coronary Artery Disease
}

\author{
Ying-Fei Bi, Jing-Yuan Mao, Xian-Liang Wang, Zhi-Qiang Zhao, Bin Li, Ya-Zhu Hou \\ Cardiovascular Department, First Teaching Hospital of Tianjin University of Chinese Medicine, Tianjin, China \\ Email: yingfei1981@126.com
}

Received 15 October 2014; accepted 12 May 2015; published 14 May 2015

Copyright (C) 2015 by authors and Scientific Research Publishing Inc.

This work is licensed under the Creative Commons Attribution International License (CC BY).

http://creativecommons.org/licenses/by/4.0/

(c) () Open Access

\begin{abstract}
Objective: To grasp the current situation of Traditional Chinese Medicine (TCM) on prevention and treatment for coronary artery disease (CAD) and the possible advantages and disadvantages. Method: Using a survey in the form of questionnaire among 60 cardiovascular disease experts, to grasp current situation of TCM on prevention and treatment of CAD and the possible advantages and disadvantages. Results: In most areas of China, CAD is common, and angina is the most common clinical type. More than $\mathbf{9 1 \%}$ experts choose to integrate traditional and western medicine for treatment and prevention of CAD. TCM proprietary medicine, traditional herbal decoction and intravenous TCM are widely used in the clinical work. Clinical advantages of TCM in the prevention of CAD that are listed in the questionnaire include improving symptoms, enhancing quality of life, increasing exercise tolerance, improving cardiac function, relieving angina, secondary prevention of myocardial infarction, etc. The shortcomings include troublesome brewing of herbal medicine, unpleasant taste of decoction, minimal clinical evidence, slow onset of effects and non-standardized prescription of medicine, etc. Conclusion: The survey reflects the present situation of clinical diagnosis and treatment of TCM on prevention and treatment of CAD to a certain extent; more accurate conclusions need the broader, deeper and large-scale clinical survey.
\end{abstract}

\section{Keywords}

Coronary Artery Disease, Traditional Chinese Medicine, Advantage, Disadvantages, Expert Survey

\section{Introduction}

Traditional Chinese Medicine (TCM) has a history as long as two thousand years in the prevention and treat-

How to cite this paper: Bi, Y.-F., Mao, J.-Y., Wang, X.-L., Zhao, Z.-Q., Li, B. and Hou, Y.-Z. (2015) Expert Survey on the Prevention and Treatment Situation of Traditional Chinese Medicine for Coronary Artery Disease. Chinese Medicine, 6, $109-114$. http://dx.doi.org/10.4236/cm.2015.62012 
ment of coronary artery disease (CAD). However, it is necessary to have a better understanding of its role in the current healthcare setting, and identify its advantages and disadvantages, so as to elevate clinical standards and increase its application. It's necessary to grasp the current situation of Traditional Chinese Medicine (TCM) on prevention and treatment for CAD and the possible advantages and disadvantages.

\section{Method}

A survey in the form of questionnaire was conducted among 60 cardiovascular disease experts who had attended the 2013 annual meeting of CAD in TCM clinical research alliance. The questionnaire requested the experts to provide their opinions on the current situation of TCM in the prevention and treatment of CAD and its advantages and disadvantages. The findings are reported as follows.

\section{Results}

\subsection{Basic Information of the Experts Who Participated in the Survey}

60 experts who participated in the investigation were from 22 provinces, municipalities and autonomous regions of China. 45 males and 15 females, aged $55.47 \pm 8.12$ years old, participated in the survey. Among them were 34 chief physicians, 26 associate chief physicians, 19 doctoral degree mentors, 35 master's degree mentors, with $26.37 \pm 5.86$ years of work experience. 53 were from TCM hospital, 3 from Western medicine hospital while 4 were from integrated Chinese and Western Medicine hospital. 58 of them come from tertiary hospitals and 2 of them were from secondary hospitals.

\subsection{Expert Authority Coefficient}

The assigned scores for the basis of judgments by the experts and the familiarity of the issues were pooled and the average coefficient of authority calculated was $0.92 \pm 0.06$. The high expert authority coefficient indicates that the survey results have high reliability.

\section{Results of the Survey}

\subsection{The Frequency of Disease}

The frequency of CAD seen by the experts in the region they belong to are shown in Table 1, the frequency is listed in increasing order.

\subsection{The Main Subtypes of Disease}

The clinical subtypes of CAD in the survey were angina pectoris (AP), arrhythmia, heart failure (HF), myocardial infarction (MI), sudden death, etc. The experts were to grade the frequency of each disease subtype according to their experience. They were to choose if it was unusual, sometimes, common, frequent and constantly and the corresponding scores were $0,1,2,3$ and 4 . Finally, the scores would be pooled (total score of 240) and average will be calculated. The responses and scores are shown in Table 2.

\subsection{The Prevention and Treatment of Disease}

The investigation on the common methods used for CAD by each experts show that only 3 experts use purely TCM, 2 experts use Western medicine only, while 55 experts use both Chinese traditional and Western medicine. The popularity and effectiveness of the prevention and treatment methods used by experts in CAD were also studied. The methods included in the investigation were TCM decoction, oral proprietary TCM, TCM intravenous preparations, oral western medicine, western medicine intravenous preparations, percutaneous coronary intervention (PCI), coronary artery bypass grafting (CABG) and combination of TCM and western medicine treatment. The popularity was assigned with 4 levels and they were not commonly used, commonly used, more commonly used and strong commonly used. The given scores for the four levels were $0,1,2$ and 3 correspondingly. The effectiveness was also assigned with 4 levels and they were no effect, effective, more effective and strong effective. The given scores for the four levels were also $0,1,2$ and 3 correspondingly. Finally, the scores would be summed (total score of 180) and average would be calculated. The responses from the experts and the 
Table 1. The frequency of disease.

\begin{tabular}{cccccc}
\hline Level & Unusual & Sometimes & Common & Frequent & Constantly \\
\hline The number of expert & 0 & 0 & 10 & 14 & 36 \\
\hline
\end{tabular}

Table 2. The inquiry on main subtypes of disease.

\begin{tabular}{|c|c|c|c|c|c|c|c|}
\hline Type/Grade & Unusual & Sometimes & Common & Frequent & Constantly & $\begin{array}{l}\text { Total } \\
\text { Score }\end{array}$ & $\begin{array}{c}\text { Average } \\
\text { Score }\end{array}$ \\
\hline $\mathrm{AP}$ & 0 & 0 & 18 & 15 & 27 & 189 & 3.15 \\
\hline Arrhythmia & 0 & 0 & 26 & 24 & 10 & 164 & 2.73 \\
\hline $\mathrm{HF}$ & 0 & 0 & 24 & 23 & 13 & 169 & 2.82 \\
\hline MI & 0 & 10 & 25 & 17 & 8 & 143 & 2.38 \\
\hline Sudden death & 2 & 33 & 19 & 5 & 1 & 55 & 0.92 \\
\hline
\end{tabular}

scores are shown in Table 3 and Table 4.

\subsection{Potential Advantages of TCM}

The potential advantages of TCM in comparison to western medicine in the prevention and treatment of CAD are listed in the questionnaire. The clinical advantages were relieving angina pectoris, improving symptoms, enhancing the quality of life, increasing exercise tolerance, improving physiochemical markers, intervening restenosis (RS) after percutaneous coronary intervention (PCI), regulating arrhythmias, improving cardiac function, secondary prevention of myocardial infarction, decreasing endpoint events, etc. The effectiveness advantages were overall conditioning, individual diagnosis, mild effect, safety, low cost, comprehensive benefit, well received by patients, etc. For the above-mentioned advantages, experts were to select from the options of no, possible, general, definite or prominent and the corresponding scores for each option were $0,1,2,3$ and 4 , at which the scores will be summed (a total of 240 points) and averaged. The result of the investigation is shown in Table 5 .

\subsection{Shortcomings of TCM}

There are still shortcomings of TCM in the prevention and treatment of CAD as compared to western medicine, they include plausible curative effect, lack of clinical evidence, slow onset of effect, non-standardized use of medication, decoction is tedious to prepare, unpleasant taste of herbal decoction, toxicity of TCM, narrow variety of TCM proprietary medicine, prominent side effect of Chinese intravenous drugs, high treatment cost, etc. Experts were to choose either yes or no according to their experience and knowledge and results is shown in Table 6.

\section{Discussion}

A person who is very knowledgeable and has great experience in a particular area will be called an expert. The viewpoint of an expert will therefore be a representation of the current level of knowledge in the particular research field. The survey gathers the experience and knowledge of the experts, analyses the results and then makes conclusions corresponding to the objective of the study.

The sixty experts who participated in this survey were from 22 different regions (province/city/municipality) of China. The experts who participated in the investigation were highly professional with high expert authority coefficient. Therefore, this survey result is reliable and scientific and can be a regional representation.

The results demonstrate that $\mathrm{CAD}$, in particular the subtype angina pectoris, is common in most regions of China. Along with the increasing standard of life and advancement in the diagnosis and treatment techniques, heart failure being the end-stage of CAD has also become more common. Arrhythmia and myocardial infarction are the presentations of CAD frequently seen.

More than $91 \%$ experts choose to integrate traditional and western medicine for treatment and prevention of CAD. The survey shows that TCM proprietary medicine, traditional herbal decoction and intravenous TCM are 
Table 3. The popularity inquiry of prevention and treatment of disease.

\begin{tabular}{|c|c|c|c|c|c|c|}
\hline Methods/Levels & $\begin{array}{c}\text { Not Commonly } \\
\text { Used }\end{array}$ & $\begin{array}{c}\text { Commonly } \\
\text { Used }\end{array}$ & $\begin{array}{c}\text { More } \\
\text { Commonly } \\
\text { Used }\end{array}$ & $\begin{array}{c}\text { Strong } \\
\text { Commonly Used }\end{array}$ & $\begin{array}{c}\text { Total } \\
\text { Scores }\end{array}$ & $\begin{array}{l}\text { Average } \\
\text { Scores }\end{array}$ \\
\hline TCM decoction & 2 & 5 & 20 & 33 & 144 & 2.40 \\
\hline Oral proprietary TCM & 2 & 1 & 22 & 35 & 150 & 2.50 \\
\hline $\begin{array}{l}\text { TCM intravenous } \\
\text { preparations }\end{array}$ & 2 & 11 & 22 & 25 & 130 & 2.17 \\
\hline $\begin{array}{l}\text { Oral western } \\
\text { medicine }\end{array}$ & 3 & 2 & 18 & 37 & 149 & 2.48 \\
\hline $\begin{array}{l}\text { Western medicine } \\
\text { intravenous preparations }\end{array}$ & 4 & 11 & 32 & 13 & 114 & 1.90 \\
\hline PCI & 9 & 15 & 17 & 19 & 106 & 1.77 \\
\hline CABG & 27 & 16 & 8 & 9 & 59 & 0.98 \\
\hline $\begin{array}{l}\text { Combination of TCM } \\
\text { and western medicine }\end{array}$ & 5 & 2 & 6 & 47 & 155 & 2.58 \\
\hline
\end{tabular}

Table 4. The effectiveness inquiry of prevention and treatment of disease.

\begin{tabular}{|c|c|c|c|c|c|c|}
\hline Methods/Levels & No Effect & Effective & $\begin{array}{c}\text { More } \\
\text { Effective }\end{array}$ & $\begin{array}{c}\text { Strong } \\
\text { Effective }\end{array}$ & Total Scores & $\begin{array}{l}\text { Average } \\
\text { Scores }\end{array}$ \\
\hline TCM decoction & 0 & 7 & 34 & 19 & 132 & 2.20 \\
\hline Oral proprietary $\mathrm{TCM}$ & 0 & 16 & 37 & 7 & 111 & 1.85 \\
\hline $\begin{array}{l}\text { TCM intravenous } \\
\text { preparations }\end{array}$ & 0 & 11 & 36 & 13 & 122 & 2.03 \\
\hline Oral western medicine & 0 & 2 & 38 & 20 & 138 & 2.30 \\
\hline $\begin{array}{l}\text { Western medicine } \\
\text { intravenous preparations }\end{array}$ & 0 & 5 & 30 & 25 & 140 & 2.33 \\
\hline PCI & 0 & 3 & 21 & 36 & 153 & 2.55 \\
\hline CABG & 0 & 4 & 29 & 27 & 143 & 2.38 \\
\hline $\begin{array}{l}\text { Combination of TCM } \\
\text { and western medicine }\end{array}$ & 0 & 1 & 11 & 48 & 167 & 2.78 \\
\hline
\end{tabular}

widely used in the clinical work, but western medicine injection, coronary artery intervention and coronary artery bypass grafting are more effective than TCM treatment. The mechanism of TCM is unclear and there is a lack of clinical evidence to support the function of the medicine; thus, healthcare providers are less confident with its use.

Moreover, the results of the survey indicate that there are greater approvals with the use of TCM decoction than proprietary medicine and intravenous drugs. This might be due to the narrow variety of proprietary medicine available and the adverse events reported in the use of intravenous drugs.

Clinical advantages of TCM in the prevention of CAD that are listed in the questionnaire include improving symptoms, enhancing quality of life, increasing exercise tolerance, improving cardiac function, relieving angina, secondary prevention of myocardial infarction, etc. These advantages have gained high recognition, and they are consistent with clinical practice and findings [1]-[5]. In addition, individualized treatment, treatment as a whole, safety, well-received by patients, mild effect and comprehensive benefits, etc. were advantages that experts valued. There are still inadequacies in TCM prevention and treatment of CAD, and most experts agree that the shortcomings include troublesome brewing of herbal medicine, unpleasant taste of decoction, minimal clinical evidence, slow onset of effects, non-standardized prescription of medicine, etc. In particular, the hassle in brewing medicine and the unpleasant taste of the decoction were the direct cause to the refusal of treatment by the patients. Currently, efforts have been made to improve traditional Chinese medicine formulations and simplify administration of medicine. The slow onset of effect is in comparison with western medicine; in fact, there are a lot of fast-acting TCM preparations for clinical use. Non-standardized medication and less clinical evidence reflect the current situation of TCM. Standardized medication helps to systematically review the group effect of 
Table 5. Investigation of potential advantages in TCM prevention and treatment of CAD.

\begin{tabular}{|c|c|c|c|c|c|c|c|}
\hline Advantage/Grade & No & Possible & General & Definite & Prominent & $\begin{array}{l}\text { Total } \\
\text { Score }\end{array}$ & $\begin{array}{l}\text { Average } \\
\text { Score }\end{array}$ \\
\hline Relieve angina pectoris & 0 & 0 & 12 & 38 & 10 & 178 & 2.97 \\
\hline Improve symptoms & 0 & 1 & 1 & 27 & 31 & 208 & 3.47 \\
\hline Enhance the quality of life & 0 & 1 & 2 & 32 & 25 & 201 & 3.35 \\
\hline Increase exercise tolerance & 1 & 3 & 2 & 34 & 20 & 189 & 3.15 \\
\hline $\begin{array}{c}\text { Improve } \\
\text { physiochemical indexes }\end{array}$ & 2 & 3 & 29 & 22 & 4 & 143 & 2.38 \\
\hline $\begin{array}{c}\text { Intervene } \\
\text { restenosis (RS) after PCI }\end{array}$ & 1 & 10 & 16 & 26 & 7 & 148 & 2.47 \\
\hline Regulate arrhythmias & 1 & 3 & 17 & 28 & 11 & 165 & 2.75 \\
\hline Improve cardiac function & 1 & 3 & 7 & 33 & 16 & 180 & 3.00 \\
\hline $\begin{array}{l}\text { Secondary prevention of } \\
\text { myocardial infarction }\end{array}$ & 1 & 3 & 6 & 39 & 11 & 176 & 2.93 \\
\hline Decrease endpoints & 1 & 4 & 20 & 24 & 11 & 160 & 2.67 \\
\hline Overall conditioning, & 0 & 0 & 0 & 20 & 40 & 220 & 3.67 \\
\hline Individual diagnosis & 0 & 0 & 0 & 14 & 46 & 226 & 3.77 \\
\hline Mild effect & 0 & 2 & 5 & 29 & 24 & 195 & 3.25 \\
\hline Safety & 1 & 2 & 5 & 22 & 30 & 198 & 3.30 \\
\hline Low cost & 2 & 1 & 31 & 12 & 14 & 155 & 2.58 \\
\hline Comprehensive benefit & 0 & 0 & 11 & 29 & 20 & 189 & 3.15 \\
\hline Well received by patients & 0 & 0 & 6 & 30 & 24 & 198 & 3.30 \\
\hline
\end{tabular}

Table 6. Shortcomings of TCM.

\begin{tabular}{|c|c|c|c|c|c|}
\hline Insufficiency/Grade & No & Yes & Insufficiency/Grade & No & Yes \\
\hline Plausible curative effect & 30 & 30 & Poor taste of medicinal borth & 7 & 53 \\
\hline Lack of clinical evidence & 10 & 50 & Toxicity of TCM & 57 & 3 \\
\hline Slow onset of effects & 11 & 49 & Few species of Chinese patent medicine & 44 & 16 \\
\hline Improper use of medication & 12 & 48 & Prominent side effect of Chinese injection & 42 & 18 \\
\hline Tedious to prepare decoction & 3 & 57 & High treatment cost & 40 & 20 \\
\hline
\end{tabular}

TCM in the prevention of CAD so as to obtain high scientific and authoritative clinical evidence.

Expert opinions and recommendations have been important clinical evidence for local and international guidelines in the treatment of CAD. The results of the survey can reflect the current clinical setting of the treatment and prevention of $\mathrm{CAD}$, which are essential guides and references for clinical use. It should also be noted that the vast majority of the experts involved in the survey are from TCM hospitals, and thus the survey result mainly reflects the basic situation in TCM hospitals. Most experts are from third grade hospitals, so it is unable to accurately reflect the situation in primary hospital. Hence, we should also carry out investigations in western hospitals and primary hospitals in the future, in order to have a complete picture of the clinical diagnosis and treatment of TCM in the prevention of CAD. This will enable us to fully recognize our advantages and disadvantages, make use of the advantages, discover potential advantages, strive to make up for our shortcomings, and make further contributions to the prevention and treatment of the disease.

\section{References}

[1] Mao, J.Y., Bi, Y.F., Zhang, B.L., et al. (2010) Study on Clinical Therapeutic Effect of Acute Coronary Syndrome Patients Treated in the Unit Integrated TCM and Western Medicine. Beijing Journal of Traditional Chinese Medicine, 29, 
10-13.

[2] Zhang, M.Z., Liu, Z.Y., Zou, X., et al. (2003) Effect of Tongguan Capsule on the Diastolic Function of Left Heart in Patients with Coronary Artery Disease. Journal of Practical Traditional Chinese Internal Medicine, 17, 81-82.

[3] Zhang, J.H., Shang, H.C., Zhang, B.L., et al. (2008) Compound Salvia Droplet Pill, a Traditional Chinese Medicine, for the Treatment of Unstable Angina Pectoris: A Systematic Review. Medical Science Monitor, 14, RA1-RA7.

[4] Lu, Z., Kou, W., Du, B., et al. (2008) Effect of Xuezhikang, an Extract from Red Yeast Chinese Rice, on Coronary Events in a Chinese Population with Previous Myocardial Infarction. The American Journal of Cardiology, 101, 16891693. http://dx.doi.org/10.1016/j.amjcard.2008.02.056

[5] Xu, H.J., Ren, M., Zhang, B.L., et al. (2010) Baseline Characteristics of Myocardial Infarction Secondary Prevention Study in Traditional Chinese Medicine (MISPS-TCM). Heart, 96, A119. http://dx.doi.org/10.1136/hrt.2010.208967.383 